\title{
Photodegradable Toners for Electrophotography II. Accelerated Photodegradation of Matrix Resin by Deep Ultraviolet-Exposure at an Elevated Temperature
}

\author{
Kazuyuki Sugita, Tomohisa Ishizawa, Hiromi Tateno, Masahito KushidA, \\ Kieko Harada, Kyoichi Saito, Nobutsune Namatame, ${ }^{*}$ and Noboru Mogi* \\ Department of Materials Technology, Chiba University, \\ Yayoi-cho, Inage-ku, Chiba 263-8522, Japan \\ * Plastic Colorants and E. I. Materials Division, Toyo Ink Mfg. Co. Ltd., \\ Aza-Matsumine, Ooaza-Nakafuku, Kawagoe-shi, Saitama 356-1156, Japan
}

(Received July 14, 1999)

\begin{abstract}
Phenyl isopropenyl ketone was terpolymerized with styrene and $n$-butyl acrylate. Clear $400 \mathrm{~nm}$ thick layers of the terpolymer on glass plates were found to be removed by brushing-off after deep ultraviolet (DUV) exposure for $3-5 \mathrm{~min}$ at room temperature or for $1 \mathrm{~min}$ at $80-115^{\circ} \mathrm{C} .1 .6 \mu \mathrm{m}$ thick polymer layers were removed by 3 times of repeated cycles of $3 \mathrm{~min}$ DUV-exposure at $100-150^{\circ} \mathrm{C}$ and brushing-off. The polymer layer irradiated under some conditions could not be detached from the substrate, and crosslinking in parallel with degradation was found to take place during DUV irradiation.

KEY WORDS Phenyl Isopropenyl Ketone Terpolymer / Clear Polymer Layer / High Sensitivity / Deep Ultraviolet / Several-Minute Exposure / Benzoyl Group Removal / Main Chain Scission / Molecular Weight Decrease / Crosslinking / Brushing-Off /
\end{abstract}

In modern highly information-oriented society, huge volume of paper is consumed for information communication and recording in the form of hardcopy: printed matter by letterpress, gravure, and lithography ; computer and facsimile outputs by thermal transfer recording; and copied documents by electrophotography or electrostatic duplication. In the first system, the pigments are trapped in the printing ink and fixed firmly to the substrate (paper or plastic film) by curing of the vehicle resin. In 2 nd the colorants contained in the resin layer are sticking on the substrate in the image area by partial fusion of the resin. In 3rd the toner powders containing pigment particles inside are fixed on the substrate or to each other by partial fusion of the toner surface. Therefore, it is the easiest to detach the image in the last system to recover the substrate by unbinding the fixed colorants.

Recently, toner images containing fadable colorants ${ }^{1}$ and detachment of toner images with a roller after swelling with a mixture of water and organic solvent ${ }^{2}$ are reported as reusing methods of copying paper, but they are still under development. Instead, we have proposed to detach the image of photodegradable toners from the substrate by mechanical action such as brushing, blowing and/or crumpling after ultraviolet (UV) light irradiation. In the previous study ${ }^{3}$ we terpolymerized phenyl isopropenyl ketone (PIPK) with styrene (St) and $n$-butyl acrylate $(\mathrm{BuA})$, which are the main components of the known toner resin for electrophotography. Clear terpolymer films were measured for spectral and molecular weight changes as well as with photodegradability by $\mathrm{mid} / \mathrm{near}$ UV or deep ultraviolet (DUV) irradiation. 400 $\mathrm{nm}$ thick films of a terpolymer were found to be removed by brushing-off after 5 min-exposure with a super-high pressure mercury lamp (SHPL) or 3 min-exposure with a low pressure mercury lamp (LPL). However, films of another terpolymer could not be removed and left their residual layers crosslinked by DUV irradiation.
In this paper we report the effects of DUV irradiation at an elevated temperature and those of film thickness on the degradability. Further, photodegradability of PIPK-St-BuA terpolymer was compared with that of PIPK-St- $n$-butyl methacrylate (BuMA) terpolymer in order to study the scheme of photochemical reaction.

\section{EXPERIMENTAL}

\section{Materials}

PIPK was prepared as was described before, ${ }^{4}$ and terpolymerized with $\mathrm{St}$ and $\mathrm{BuA}$ (or BuMA) in suspension by using $\alpha, \alpha^{\prime}$-azobis(isobutyronitrile) (AIBN) as the initiator similarly as stated before. ${ }^{5,6}$ The product was reprecipitated from benzene/ethanol system. The terpolymerization ratio in moles, molecular weight, glass transition temperature $\left(T_{\mathrm{g}}\right)$, and softening point $\left(T_{\mathrm{s}}\right)$ were determined by NMR, ${ }^{7}$ GPC, DSC, and Shimadzu Flow Tester, respectively. The BuA and BuMA content in Terpolymers $\mathrm{E}$ and $\mathrm{F}$, respectively, were also determined by titration with sulfuric acid after saponification with excess sodium hydroxide in aqueous 2-butanone. The polymer data are summarized in Table I. Terpolymer C, prepared by emulsion polymerization and used in the previous paper, ${ }^{3}$ is cited here again for comparison.

\section{Polymer Film Preparation and UV Irradiation}

Clear terpolymer layers were spincoated from tetrahydrofuran solutions onto glass or quartz plates, and prebaked at $90^{\circ} \mathrm{C}$ for $20 \mathrm{~min}$. The layer was irradiated in the

Table I. Summary of polymer data

\begin{tabular}{ccccccr}
\hline $\begin{array}{c}\text { Ter- } \\
\text { polymer }\end{array}$ & $\begin{array}{c}\text { Composition } \\
\text { PIPK : St : BuA }\end{array}$ & $M_{w}$ & $M_{n}$ & $M_{w} / M_{n}$ & $\frac{T_{\mathrm{g}}}{{ }^{\circ} \mathrm{C}}$ & \multicolumn{1}{c}{$T_{\mathrm{s}}$} \\
\hline $\mathrm{C}$ & $12: 69: 19$ & 44000 & 17000 & 2.6 & 75 & 102 \\
$\mathrm{E}$ & $45: 44: 11$ & 12300 & 7400 & 1.7 & 58 & 90 \\
$\mathrm{~F}$ & $40: 38: 22$ (BuMA) & 13000 & 6300 & 2.1 & 73 & 116 \\
\hline
\end{tabular}




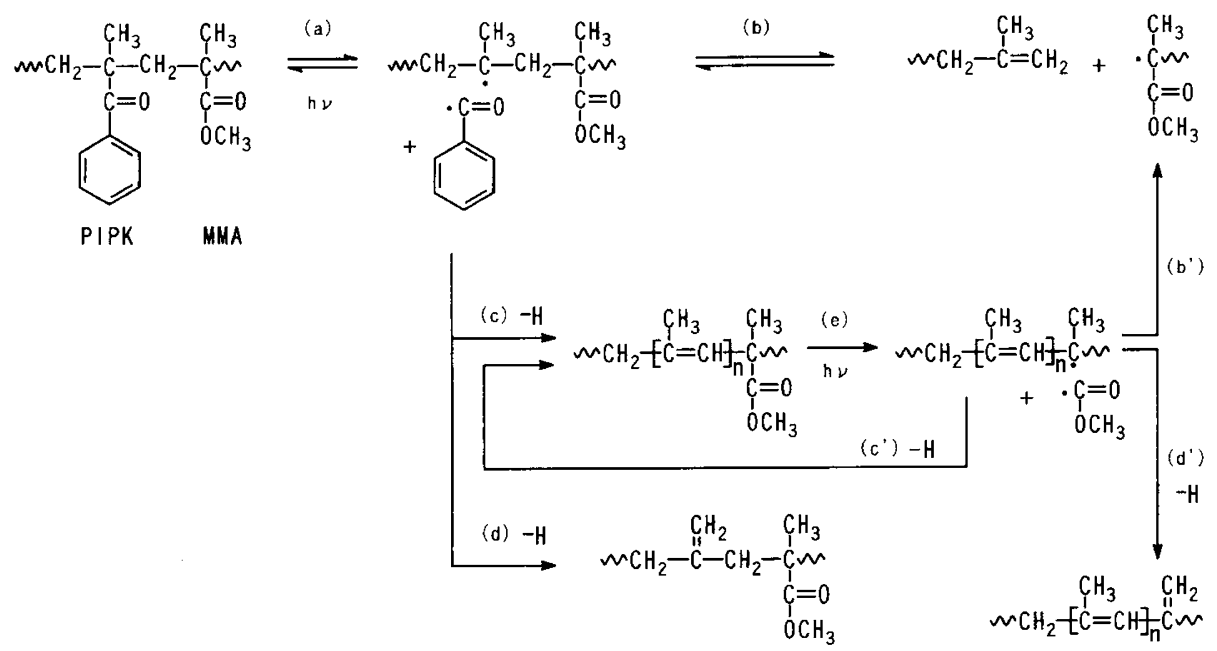

Figure 1. Degradation scheme of PMMA-PIPK: (a) photolysis of benzoyl side group by Norrish Type I, (b, b') $\beta$-scission, (c,d) hydrogen abstraction, (e) photolysis of ester side group on the carbon atom adjacent to the $\mathrm{C}=\mathrm{C}$ bond, and ( $\left.c^{\prime}, \mathrm{d}^{\prime}\right)$ hydrogen abstraction leading to extension of conjugate double bond.

air from a distance of $10 \mathrm{~cm}$ with a LPL, Toshiba GL-8, of $8 \mathrm{~W}$, the emission from which can be regarded as a monochromatic radiation at $254 \mathrm{~nm}$. The light intensity was measured to be $0.63 \mathrm{~mW} \mathrm{~cm}^{-2}$ with a thermopile, Eppley Thermopile (Air Type).

\section{Measurements of Benzoyl Side-Group Removal and Main-Chain Scission}

Concentration of remaining benzoyl groups was calculated from the absorbance at $242 \mathrm{~nm}$, and the number of absorbed photons was from the absorbance at $254 \mathrm{~nm}$ in the UV spectra, where the $\varepsilon_{242}$ and $\varepsilon_{254}$ values used were 12700 and $7600 \mathrm{~L} \mathrm{~mol}^{-1} \mathrm{~cm}^{-1}$, respectively.

The number of moles of the benzoyl side-group removal, $R_{n}$, and quantum yield for side-group removal, $\Phi_{\mathrm{SR}}$, are calculated by eq 1 :

$$
\Phi_{\mathrm{SR}}=R_{n} / I_{\mathrm{abs}}=\left(A_{0}-A\right) / \varepsilon_{242} / I_{\mathrm{abs}}
$$

where, $A_{0}$ and $A$ are absorbance of the polymer layer of thickness $d$ before and after DUV irradiation, respectively, and $I_{\text {abs }}$ is the number of moles of photons (in einstein) absorbed by the polymer sample of unit area ( 1 $\mathrm{cm}^{2}$ ).

The polymer layer was dipped in toluene, and an aliquot of the toluene solution was injected into the GPC to measure the molecular weights before and after DUV irradiation at various temperatures. In some cases traces of residue insoluble in toluene was observed to remain on the substrate, though the mass could not be weighed. The number of moles of the main-chain scission, Sn, and quantum yield for main-chain scission, $\Phi_{\mathrm{CS}}$, are calculated by eq 2 :

$$
\Phi_{\mathrm{CS}}=S_{n} / I_{\mathrm{abs}}=\left(M_{n_{0}} / M_{n}-1\right) m / M_{n 0} / I_{\mathrm{abs}}
$$

where, $M_{n_{0}}$ and $M_{n}$ are number-averaged molecular weights before and after DUV irradiation, respectively, and $m$ is a sample mass in $g$.

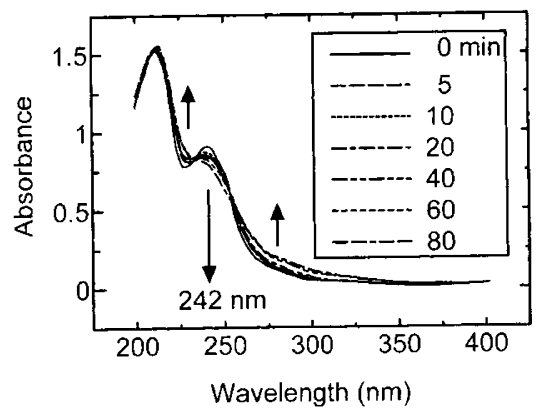

Figure 2. UV spectral change of Terpolymer E layer by DUV irradiation (thickness : $162 \mathrm{~nm}$ ).

\section{RESULTS AND DISCUSSION}

Temperature Dependence of Quantum Yields for Benzoyl Side-Group Removal and for Main-Chain Scission. Part 1a. $400 \mathrm{~nm}$ Thick Films

It has been clarified that the primary photoprocess in degradation scheme of PIPK copolymer with methyl methacrylate (PMMA-PIPK) is Norrish Type I removal of benzoyl side groups to form polymer radicals (Figure 1 , a) followed by $\beta$-scission of main chains (b, 2.5-10\%) and by hydrogen abstraction on the next carbon atoms to form $\mathrm{C}=\mathrm{C}$ bonds in the main chain or in the side chain (c and d, 97.5-90\%), and that the scheme includes further Norrish Type I cleavage of ester side groups on the carbon atoms adjacent to the $\mathrm{C}=\mathrm{C}$ bonds (e) followed by $\beta^{\prime}$-scission of the main chain. ${ }^{8}$

Clear $400 \mathrm{~nm}$ thick layers of Terpolymers $\mathrm{E}$ and $\mathrm{F}$ were DUV-irradiated, and measured for UV spectrum and GPC. An example of the spectral change for a Terpolymer E layer (thickness : $162 \mathrm{~nm}$ ) is shown in Figure 2. Since UV spectral changes of PIPK-St-BuA and PIPKSt-BuMA terpolymers studied in this paper were similar to that of PMMA-PIPK copolymers, the chemistry indicated in Figure 1 is considered to hold also for the degradation photoprocess of Terpolymers $\mathrm{E}$ and F. It was cal- 


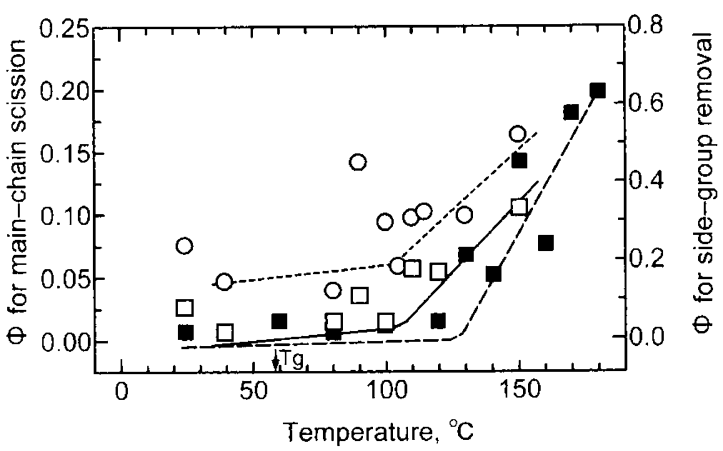

Figure 3. Temperature dependence of quantum yields for mainchain scission ( $\square$ and $\square$ ) and for side-group removal $(\bigcirc)$ of Terpolymer E layers of $400 \mathrm{~nm}$ thick $(\square$ and $\bigcirc)$ and $1.6 \mu$ m thick $(\square)$.

culated from the absorbance at $254 \mathrm{~nm}$ that the polymer films of $400 \mathrm{~nm}$ and $1.6 \mu \mathrm{m}$ thickness transmit $6.3 \%$ and $0.0016 \%$ of incident DUV light, respectively.

The quantum yields, $\Phi_{\mathrm{SR}}$ and $\Phi_{\mathrm{CS}}$, were calculated from the spectral and GPC changes during initial 1 or 2 min of DUV exposure for Terpolymer E, and are plotted against the irradiating temperature in Figure 3. Both quantum yields increased abruptly above a critical temperature at $100-105^{\circ} \mathrm{C}$, which is 45 degree higher than $T_{\mathrm{g}}$. With Terpolymer $\mathrm{F}$, in which BuA was replaced by BuMA, the quantum yield for main-chain scission increased markedly above $95^{\circ} \mathrm{C}$, which is 20 degree higher than $T_{\mathrm{g}}$, but the quantum yield for benzoyl side-group removal did not show a definite critical temperature.

Temperature Dependence of Photodegradability and Detachability from Substrates. Part $16.400 \mathrm{~nm}$ Thick Films

The clear polymer layers were DUV-irradiated and rubbed down 100 times with a paint brush to estimate the degradability, and the results are indicated in the left half of Table II. The layers of Terpolymer $\mathbf{E}$ were removed off by brushing after 3 min-exposure at room temperature and after 1 min-exposure at $80-115^{\circ} \mathrm{C}$, while they could not be removed completely at and above 120 ${ }^{\circ} \mathrm{C}$ and left residual layers on the substrate.

As for Terpolymer F, the $400 \mathrm{~nm}$ thick layers were removed after 3 min-exposure at room temperature, $2 \mathrm{~min}$ at $90^{\circ} \mathrm{C}$ and $1 \mathrm{~min}$ at $120^{\circ} \mathrm{C}$, but they could not at $150^{\circ} \mathrm{C}$.

The increased quantum yields and the accelerated detachability at higher temperature were ascribed to increased free volume, which allows for polymer radicals and low-molecular-weight photoproducts to escape from the cage without taking part in recombination after Type I photofragmentation. It is assumed that the residual layer formation by DUV-irradiation at and above $120^{\circ} \mathrm{C}$ for Terpolymer $\mathrm{E}$ and at $150^{\circ} \mathrm{C}$ for Terpolymer $\mathrm{F}$ was due to partial crosslinking caused by hydrogen abstraction from other polymer molecules and/or by recombination between the polymer radicals. Traces of the toluene-insoluble residue left on the substrate and an increase of $M_{w} / M_{n}$ after DUV-exposure for $5 \mathrm{~min}$ at and above $120^{\circ} \mathrm{C}$ for Terpolymer $\mathrm{E}$ also support this assumption.

\begin{tabular}{|c|c|c|c|c|c|c|c|c|c|c|}
\hline \multirow[b]{3}{*}{ Temp. } & \multicolumn{4}{|c|}{$400 \mathrm{~nm}$ thick } & \multicolumn{6}{|c|}{$1.6 \mu \mathrm{m}$ thick } \\
\hline & \multicolumn{9}{|c|}{ Irradiation time (min) } & \multirow[b]{2}{*}{5} \\
\hline & 0 & 1 & 3 & 5 & 0 & 1 & 2 & 3 & 4 & \\
\hline \multirow{2}{*}{$\begin{array}{l}\text { r.t. } \\
40^{\circ} \mathrm{C} \\
60\end{array}$} & 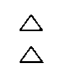 & $\stackrel{0}{0}$ & (9) & (1) & $\triangle$ & $\triangle$ & $\triangle$ & 0 & $\triangle$ & $\triangle$ \\
\hline & & & & & $\triangle$ & $\triangle$ & $\triangle$ & $\triangle$ & $\triangle$ & $\triangle$ \\
\hline $\begin{array}{l}80 \\
90\end{array}$ & $\triangle \Delta$ & $\begin{array}{l}\text { (0) } \\
\text { (0) }\end{array}$ & (2) & (9) & $\triangle$ & $\triangle$ & $\triangle$ & $\triangle$ & $\triangle$ & 0 \\
\hline 100 & $\triangle$ & (0) & 0 & 0 & $\triangle$ & $\triangle$ & 0 & 0 & 0 & $\triangle$ \\
\hline 105 & $\triangle$ & (0) & 0 & 0 & & & & & & \\
\hline 110 & $\triangle$ & (C) & 0 & $\triangle$ & & & & & & \\
\hline 115 & $\triangle$ & (C) & $\triangle$ & $\triangle$ & & & & & & \\
\hline 120 & $\triangle$ & 0 & $\triangle$ & O & $\triangle$ & 0 & 0 & $\triangle$ & 0 & $\triangle$ \\
\hline 130 & $\triangle$ & 0 & $\triangle$ & $\triangle$ & $\triangle$ & 0 & 0 & 0 & 0 & 0 \\
\hline 140 & & & & & $\triangle$ & $\triangle$ & $\triangle$ & $\Delta$ & $\triangle$ & $\triangle$ \\
\hline 150 & $\triangle$ & 0 & $\triangle$ & $\triangle$ & $\triangle$ & 0 & 0 & 0 & 0 & 0 \\
\hline 160 & & & & & $\triangle$ & & & & & \\
\hline 180 & & & & & $\triangle$ & $\Delta$ & $\triangle$ & $\Delta$ & 0 & 0 \\
\hline
\end{tabular}

${ }^{a} \triangle$, layer was slightly damaged by brushing; $\bigcirc$, layer was partly removed; (O), layer was completely removed.

Temperature Dependence of Quantum Yield for Main Chain Scission and Photodegradability. Part 2. 1.6 $\mu \mathrm{m}$ Thick Films

Clear $1.6 \mu \mathrm{m}$ thick layers of Terpolymer E were DUVirradiated, and quantum yield for main-chain scission and the detachability from the substrate are shown as a function of the irradiating temperature in Figure 3 and in the right half of Table II, respectively. The quantum yield increased abruptly above a critical temperature at $120-125^{\circ} \mathrm{C}$, which is 20 degree higher than the temperature observed with the $400 \mathrm{~nm}$ thick polymer layers. A slightly improved photodegradability was observed at $130-170^{\circ} \mathrm{C}$, but the layer was not cleared off from the substrate at any temperature or after prolonged DUVirradiation. This should be caused by little penetration of DUV light into the inner part of the polymer layer thicker than $1.0 \mu \mathrm{m}$ as stated in Part 1a of this Results and Discussion Section. Other reasons to be considered are suppressed quantum yield and crosslinking in the inner part of the thick layer : polymer radicals and lowmolecular-weight photoproducts were difficult to escape from the cage and easy to recombine to regenerate the original chain bonds or to form crosslinkages.

Detachability of Thick Polymer Layers from the Substrate by Repeated Cycles of DUV-Exposure and Brushing

Clear $1.6 \mu \mathrm{m}$ thick layers of Terpolymer E were DUVirradiated for 1 or $3 \mathrm{~min}$ and brushed repeatedly. The results are shown in Table III. Three times of repeated cycles of $3 \mathrm{~min}$ DUV-irradiation at $100-150^{\circ} \mathrm{C}$ and $100-$ time rubbing-down was found to be effective for detaching the thick layer from the substrate. Clear $2.2 \mu \mathrm{m}$ thick layers of Terpolymer $\mathbf{F}$ were also detached by 3 times of repeated cycles of 3 min DUV-irradiation at 90 ${ }^{\circ} \mathrm{C}$ and 200-time rubbing-down. Removing degraded molecules at the surface sublayer and refreshing the surface of the thick layer should be effective for photofragmentation and evaporation of the photoproducts in the inner part. 
Table III. Photodegradability of $1.6 \mu \mathrm{m}$-thick terpolymer E layers after repeated DUV-irradiation and brushing ${ }^{a}$

\begin{tabular}{|c|c|c|c|c|c|c|c|c|}
\hline Irrad.time (min) & & & & & & & & \\
\hline Repetition & $\times 1$ & $\times 2$ & $\times 3$ & $\times 4$ & $\times 1$ & $\times 2$ & $\times 3$ & $\times 4$ \\
\hline $\begin{array}{l}60^{\circ} \mathrm{C} \\
80\end{array}$ & $\begin{array}{l}\triangle \\
\triangle\end{array}$ & 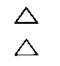 & $\Delta$ & 0 & $\triangle$ & $\begin{array}{l}\triangle \\
\triangle\end{array}$ & 0 & \\
\hline $\begin{array}{l}100 \\
120 \\
130 \\
150\end{array}$ & $\begin{array}{l}\triangle \\
\triangle \\
\triangle \\
\triangle\end{array}$ & $\begin{array}{l}0 \\
0 \\
0 \\
\triangle\end{array}$ & $\begin{array}{l}0 \\
0 \\
0\end{array}$ & $\begin{array}{l}0 \\
0 \\
0\end{array}$ & $\begin{array}{l}0 \\
0 \\
0\end{array}$ & $\begin{array}{l}0 \\
0 \\
0\end{array}$ & $\begin{array}{l}\text { () } \\
\text { (0) } \\
\text { (0) } \\
\text { (0) }\end{array}$ & (1) \\
\hline $\begin{array}{l}160 \\
170\end{array}$ & 0 & 0 & 0 & $\begin{array}{l}0 \\
0\end{array}$ & $\triangle$ & $\begin{array}{l}0 \\
\triangle\end{array}$ & 8 & \\
\hline 180 & $\triangle$ & $\Delta$ & $\triangle$ & 0 & $\triangle$ & $\Delta$ & $\triangle$ & \\
\hline
\end{tabular}

${ }^{a} \Delta$, layer was slightly damaged by brushing; $O$, layer was partly removed ; (), layer was completely removed ; - most of the layer was removed, leaving a thin residual layer.

However, formation of the residual layer and larger $M_{w} / M_{n}$ than 3.0 after DUV-irradiation at and above 160 ${ }^{\circ} \mathrm{C}$ for Terpolymer $\mathrm{E}$ and at $120^{\circ} \mathrm{C}$ for Terpolymer $\mathrm{F}$ indicates that crosslinking was also accelerated at the same time.

\section{Photochemical Reactions of PIPK Copolymer}

In the previous study, ${ }^{3}$ Terpolymer $\mathrm{C}$ degraded successfully, but another terpolymer with higher BuA content did not. It was then considered that crosslinking leading to formation of the residual layer was mainly ascribed to BuA. Terpolymer $\mathrm{E}$ in this work is of lower BuA content than Terpolymer C, and Terpolymer F contains BuMA in place of BuA.

Terpolymers $E$ and $F$, none the less, were found to leave still residual layers due to crosslinking under certain DUV-irradiation conditions.

Since it is sure that the main contribution to crosslinking is not done by hydrogen abstraction from $\mathrm{BuA}$, the crosslinking may take place either through hydrogen abstraction from St or other units in polymer chains or through direct recombination between the polymer radi- cals formed by benzoyl or butoxy-carbonyl side-group removal. DUV-irradiation at an elevated temperature was found actually to accelerate degradation and crosslinking at the same time. As for the next stage it will be essential for effective detachment of polymer layers from the substrate to find out the most suitable conditions, under which degradation is promoted much better than crosslinking.

\section{CONCLUSION}

Phenyl isopropenyl ketone was terpolymerized with styrene and $n$-butyl acrylate, which are the main components of the binder polymer for electrophotographic toners. Clear $400 \mathrm{~nm}$ thick polymer layers on glass plates were found to be removed by brushing-off after DUVexposure for $3-5 \mathrm{~min}$ at room temperature. DUVirradiation at $80-115^{\circ} \mathrm{C}$ accelerated the photodegradability. $1.6 \mu \mathrm{m}$ thick polymer layers could not be detached from the substrate even after prolonged DUV irradiation, and, however, the layers were removed by 3 times of repeated cycles of 3 min DUV-exposure at $100-$ $150^{\circ} \mathrm{C}$ and brushing-off.

\section{REFERENCES}

1. Showa-Denko Co., Japan Patent Publication, 1993-134448.

2. Ricoh Co., Japan Patent Publication, 1994-250570.

3. K. Sugita, M. Shimizu, T. Okuno, M. Kushida, K. Harada, K. Saito, N. Namatame, and N. Mogi, Polym. J., 28, 637 (1996).

4. K. Sugita, T. Kilp, and J. E. Guillet, J. Polym. Sci., Polym. Chem. Ed., 14, 1901 (1976).

5. K. Sugita, N. Ueno, K. Harada, M. Kushida, Y. Suzuki, Y. Takeuchi, and J. Guillet, Polym. J., 25, 1059 (1993).

6. Y. Takeuchi, J. E. Guillet, K. Sugita, N. Ueno, K. Harada, and Y. Suzuki, J. Polym. Sci., Part A: Polym. Chem., 34, 789 (1996).

7. I. Gitsov and O. G. Todorova, J. Appl. Polym. Sci., 40, 1631 (1992).

8. K. Sugita, T. Ishida, M. Kushida, K. Harada, K. Saito, and N. Ueno, Can. J. Chem., 73, 1841 (1995). 